\title{
One-level mini-open pedicle subtraction osteotomy for treating spinal kyphosis in patients with ankylosing spondylitis
}

\author{
Yu Wang, Chunde Li, Long Liu and Longtao Qi
}

\begin{abstract}
Background: To report a mini-open pedicle subtraction osteotomy (PSO) technique, to summarize the 2-year follow-up results of 25 patients, and to describe a modified operating table which allows the osteotomy to be closed in a more controllable manner.

Methods: We retrospectively reviewed the records of patients with AS who received one-level mini-open PSO between July 2015 and January 2018. The 25 patients with complete medical records and 2-year radiographic follow-up were included in the analysis. Estimated blood loss, operation time, incision length, complications, bed rest period, and length of hospitalization were extracted from the medical records and recorded.

Results: The mean age of the 25 patients (22 males and 3 females) was 39.5 years. The average global kyphosis(GK) decreased from $70.2^{\circ}$ before surgery to $22.3^{\circ}$ after surgery; the average C7- sagittal vertical axis (C7-SVA) decreased from $15.5 \mathrm{~cm}$ before surgery to $5.1 \mathrm{~cm}$ after surgery; the average pelvic incidence(PT) decreased from $37.8^{\circ}$ before surgery to $22.5^{\circ}$ after surgery. The average length of the incision was $10.2 \mathrm{~cm}$. The average surgical time was $263.0 \mathrm{~min}$, the average estimated blood loss was $840.0 \mathrm{ml}$, and the average time to mobilization was 4.1 days.

Conclusions: The current report shows that one-level PSO can be performed through an incision of about $10 \mathrm{~cm}$. The one-level mini-open PSO could be superior to traditional PSO surgery with respect to cosmetic outcomes. Further comparative studies are necessary to evaluate the current and conventional techniques.
\end{abstract}

Keywords: Ankylosing spondylitis, Kyphosis, Pedicle subtraction osteotomy, Vertebral decancellation, Mini-open, Minimally invasive

\section{Background}

Ankylosing spondylitis (AS) is a chronic inflammatory disease that can lead to ossification of the joints and ligaments of the spine. AS-related thoracolumbar kyphotic deformity is a disabling condition that affects more than $30 \%$ of patients with AS. Osteotomy is extensively used to correct AS-related kyphosis, and 2 main types of osteotomy are used: Smith-Petersen osteotomy (SPO) and pedicle subtraction osteotomy (PSO) [1-7].

\footnotetext{
* Correspondence: 06340@pkufh.com

Department of Orthopaedics, Peking University First Hospital, 100034 Beijing, China
}

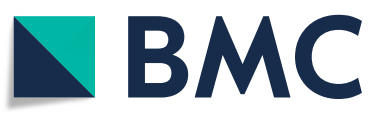

(-) The Author(s). 2021 Open Access This article is licensed under a Creative Commons Attribution 4.0 International License, which permits use, sharing, adaptation, distribution and reproduction in any medium or format, as long as you give appropriate credit to the original author(s) and the source, provide a link to the Creative Commons licence, and indicate if changes were made. The images or other third party material in this article are included in the article's Creative Commons licence, unless indicated otherwise in a credit line to the material. If material is not included in the article's Creative Commons licence and your intended use is not permitted by statutory regulation or exceeds the permitted use, you will need to obtain permission directly from the copyright holder. To view a copy of this licence, visit http://creativecommons.org/licenses/by/4.0/ The Creative Commons Public Domain Dedication waiver (http://creativecommons.org/publicdomain/zero/1.0/) applies to the data made available in this article, unless otherwise stated in a credit line to the data. phosis are usually associated with long incisions, extensive soft tissue destruction, long operative time, and significant blood loss $[8,9]$. Major complications have been reported in up to one-third of patients with ASrelated kyphosis who receive an osteotomy procedure [9-14]. As such, developing less invasive methods of osteotomy is a topic of the current research. One such method is that described by Wang and Chou: a miniopen approach for PSO which combines percutaneous screw placement and a 3-column osteotomy [15-17]. In our practice, we also developed a method that is 
performed in a mini-open fashion. By improving operating procedure and using a modified operating table, we have found that it is possible to perform a PSO via a 10$\mathrm{cm}$ incision.

Since 2015, we have performed a one-level miniopen PSO for select patients with AS. The purpose of this report is to describe the mini-open PSO technique, and to summarize the 2-year follow-up results of 25 patients.

\section{Methods}

\section{Patient selection}

We retrospectively reviewed the records of patients with AS who received one-level mini-open PSO between July 2015 and January 2018. The 25 patients with complete medical records and 2-year radiographic follow-up were included in the analysis. Estimated blood loss, operation time, incision length, complications, bed rest period, and length of hospitalization were extracted from the medical records and recorded.

\section{Radiographic follow-up}

Radiographic measurements were performed using the radiology department picture archiving and communication system. Preoperative, immediate postoperative and 2-year postoperative standing anteroposterior and lateral digital radiographs were reviewed (Fig. 1).

\section{Surgical technique}

A modified operating table that allows adjustment of the spinal alignment of AS patients during surgery is used for one-level mini-open PSO. After the PSO has been completed, the kyphotic deformity of an AS patient can be gradually corrected by manipulating the operating table (Fig. 2). This method increases control of the correction, and decreases the operative risks.

Typically, a one-level mini-open PSO begins with placement of screws at L1 and L3, followed by a PSO at $\mathrm{L} 2$, and then finally placement of screws at T12 and L4. All of the procedures are performed through one incision.

Specifically, a midline skin incision of about $10 \mathrm{~cm}$ beginning at L1 and ending at L3 is made. The paravertebral muscles are detached and the laminae are exposed bilaterally, as in traditional open surgery. After exposure, 4 pedicle screws (multi-axial, long-arm) are inserted at the level of L1 and L3, and screw position is checked by fluoroscopy. If all of the screws are deemed to be wellplaced, an L2 PSO is performed. Immediately prior to completion of the PSO, 2 short rods are inserted and locked to the screws to prevent vertebral subluxation. Once the PSO is finished, the modified operating table is manipulated and the nuts on the L1 level screws are loosened. With gradually manipulation of the operating table the kyphotic deformity is corrected accordingly. When the V-shaped osteotomy is closed completely, the

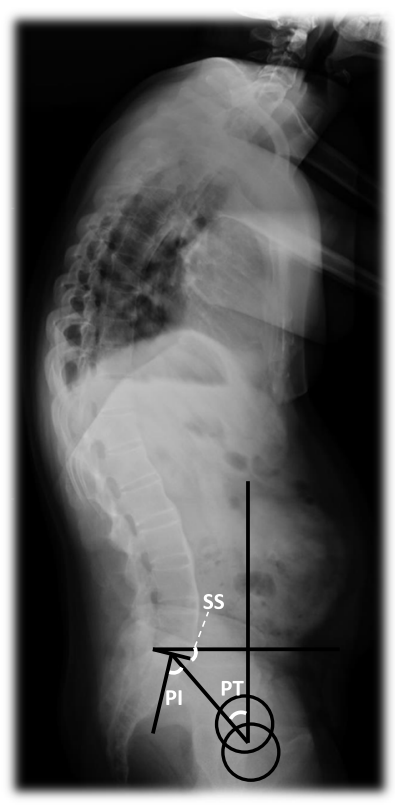

Pre-op

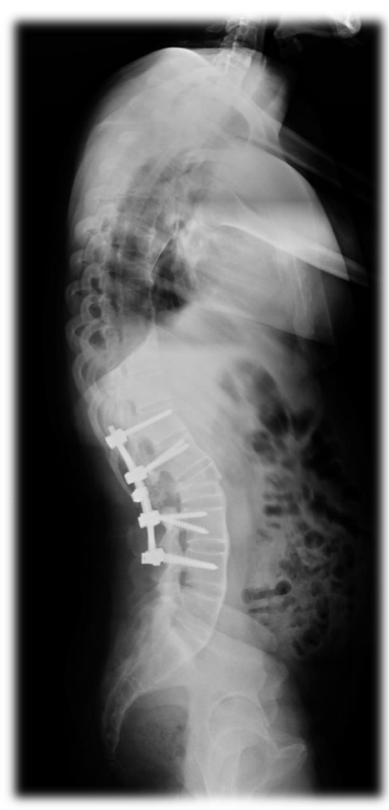

Post-op

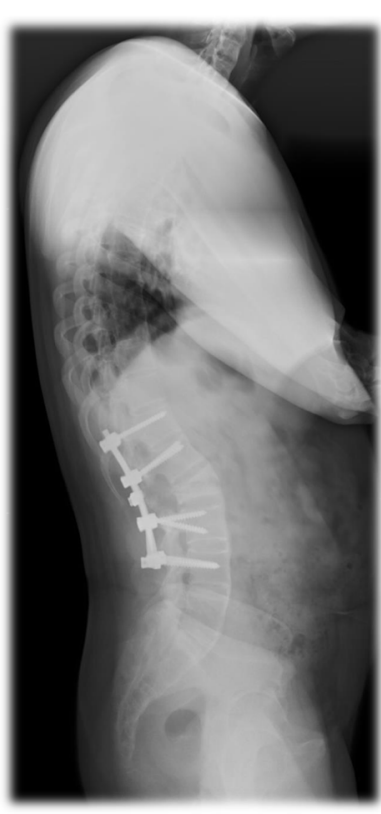

2-year

Fig. 1 Preoperative, immediate postoperative and 2-year postoperative standing anteroposterior and lateral digital radiographs were reviewed 


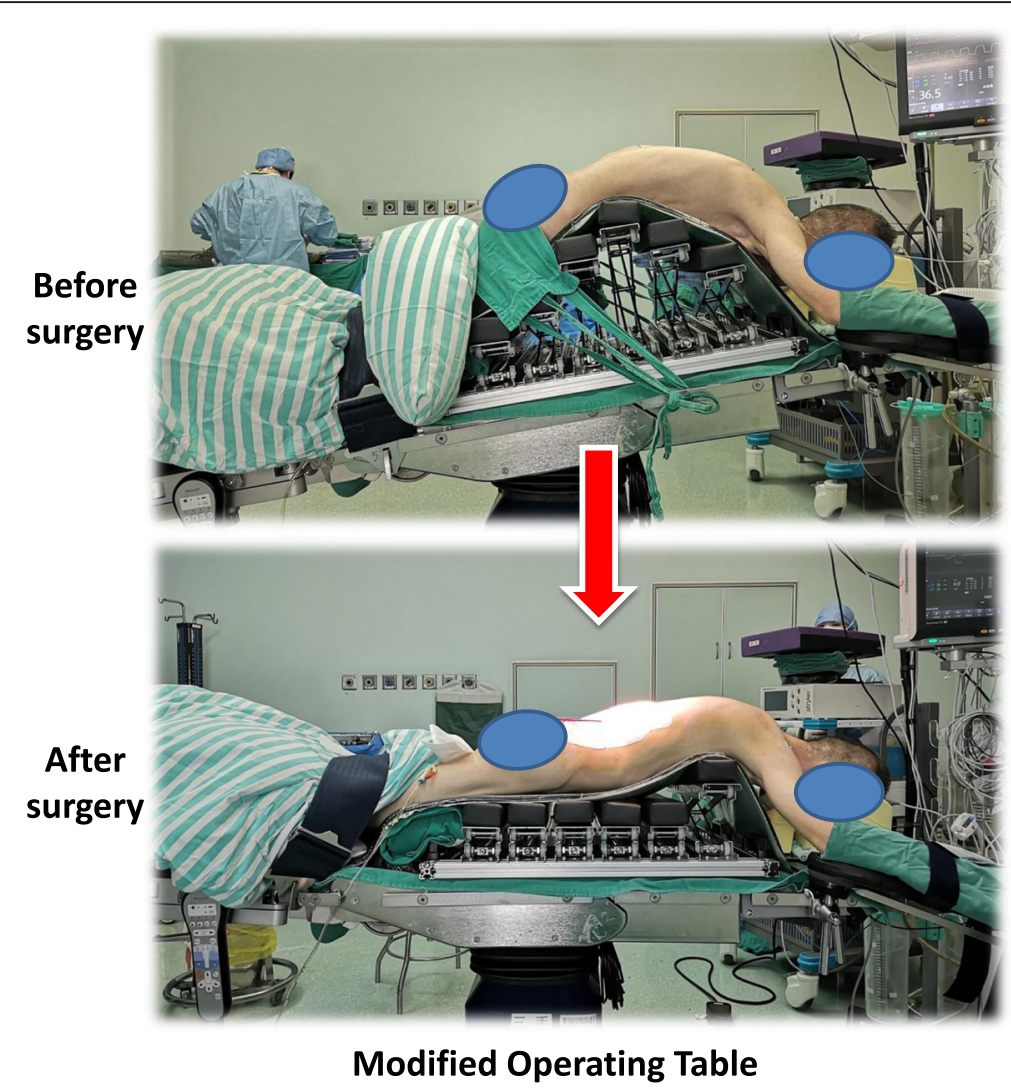

Fig. 2 The modified operating table consists of 6 supports, and the height of each support can be adjusted separately. This allows the shape of the operating table to be adjusted to fit that of the patient. In addition, adjusting the supports allows the osteotomy to be closed in a more controllable manner so that vertebral subluxation can be prevented

nuts are locked again. As a result, the posterior portion of the spine is shortened around $5 \mathrm{~cm}$, and T12 and L4 move closer towards L2. Thus, the facet joints of T12 and L4 can be reached through the existing incision (Fig. 3).

The facet joints are then exposed, and 4 screws are inserted at the level of T12 and L4 and fluoroscopy is performed to check their positions. If all the screws appear to be well-placed, the 2 short rods are replaced by 2 long rods. Somatosensory evoked potentials are monitored during the whole procedure. A drainage tube is inserted, and the incision is closed in layers. The drainage tube is removed when the daily drainage amount is $<100 \mathrm{ml}$. Typically, the patient is mobilized 3-4 days after surgery, and discharged 7-8 days after surgery (Fig. 4).

\section{Results}

The mean age of the 25 patients (22 males and 3 females) who underwent one-level mini-open PSO was 39.5 years(range: $27-56$ years).

\section{Radiographic follow-up}

The average global kyphosis(GK) decreased from $70.2^{\circ}$ before surgery to $22.3^{\circ}$ after surgery; the average C7- sagittal vertical axis (C7-SVA) decreased from $15.5 \mathrm{~cm}$ before surgery to $5.1 \mathrm{~cm}$ after surgery; the average pelvic incidence $(\mathrm{PT})$ decreased from $37.8^{\circ}$ before surgery to $22.5^{\circ}$ after surgery (Table 1 ).

\section{Intraoperative and postoperative results}

The average length of the incision was $10.2 \pm 1.2 \mathrm{~cm}$ (Table 2). The average surgical time was $263.0 \pm$ $50.4 \mathrm{~min}$, the estimated blood loss was $840.0 \pm 417.1 \mathrm{ml}$, and the average time to mobilization was $4.1 \pm 1.3$ days.

\section{Complications}

No deaths, complete paralysis, or vascular complications occurred, and no patient required a revision surgery. No implant-related complication was found. 3 patients experienced cerebrospinal fluid leak due to a dural tear. 


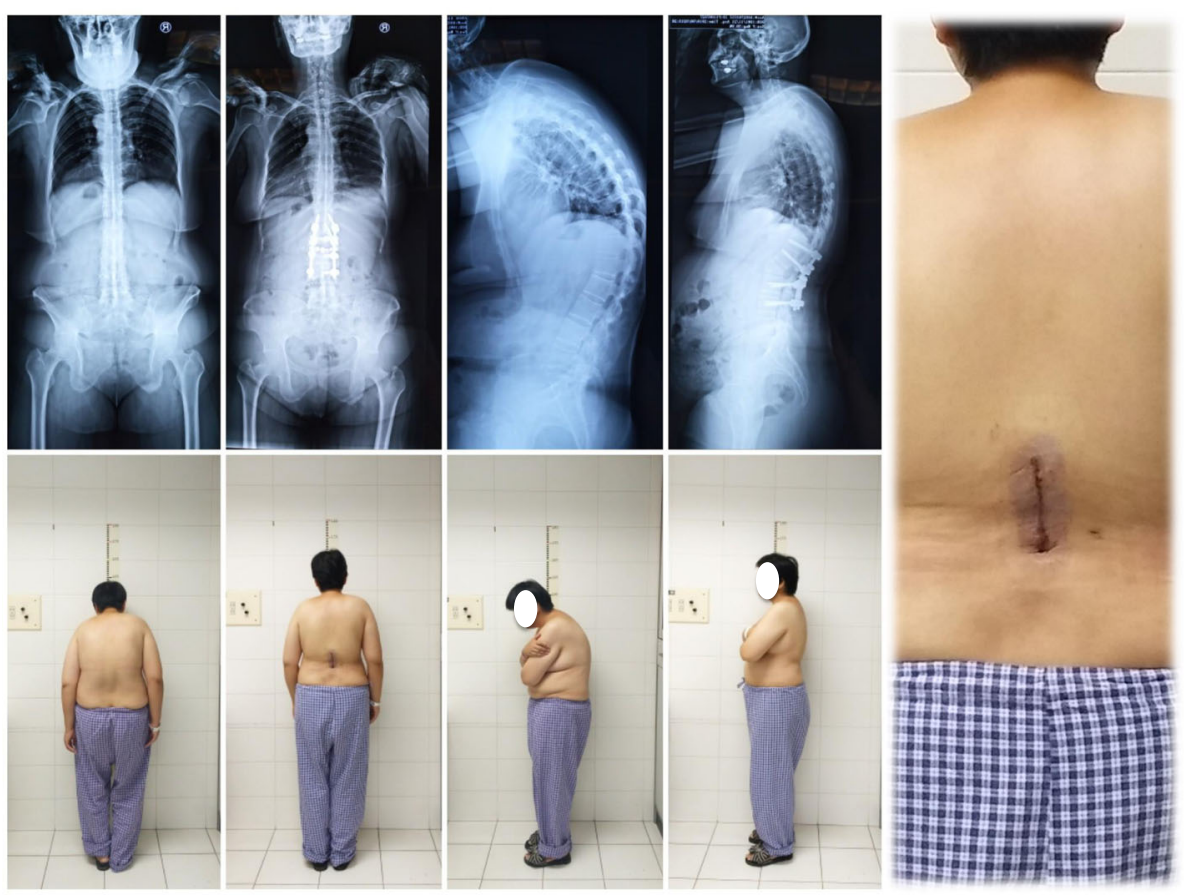

Fig. 3 A 37-year-old female with AS and thoracolumbar kyphosis. The global kyphosis angle decreased from 72.3 preoperatively to $24.7 r$ after surgery. The length of the incision was $9.8 \mathrm{~cm}$

\section{Discussion}

PSO is widely used for treating AS-related kyphosis. The procedure was first described by Thomasen in 1985 . PSO involves removal of posterior spinal elements, and a transpedicular wedge osteotomy of the vertebral body. When the wedge osteotomy is closed, the kyphotic deformity is corrected accordingly. As reported by many other authors, the mean correction achieved by onelevel PSO ranges from $30^{\circ}$ to $45^{\circ}[2,18-20]$.

\section{Can PSO be less invasive?}

PSO is one of the most invasive spine surgeries, and as such a topic of current research is how to make the procedure less invasive. Wang and Madhavan described a

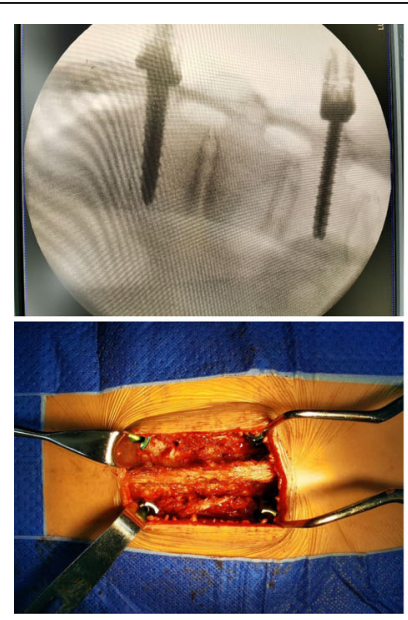

Before Osteotomy

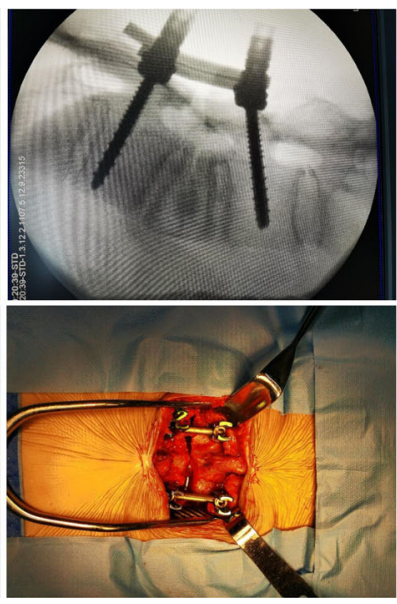

After Osteotomy

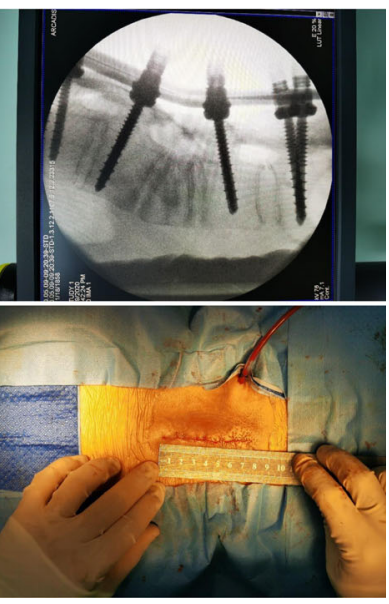

After Closure

Fig. 4 A midline skin incision of about $8 \mathrm{~cm}$ was made. After exposure, 4 pedicle screws (multi-axial, long-arm) were inserted at the level of L1 and $\mathrm{L} 3$, and screw position was checked by fluoroscopy. When the $\mathrm{V}$-shaped osteotomy was closed completely, 4 screws were inserted at the level of T12 and L4, and then 2 long rods were instrumented 
Table 1 Radiographic follow-up

\begin{tabular}{lllll}
\hline Radiographic parameters & Preoperative & Postoperative & 2-year follow-up & Final correction \\
\hline TK $\left(^{\circ}\right)$ & $41.8 \pm 14.8$ & $43.3 \pm 13.5$ & $42.1 \pm 12.8$ & $0.3 \pm 9.2$ \\
LL( $\left(^{\circ}\right)$ & $-0.9 \pm 18.4$ & $-40.4 \pm 16.3$ & $-39.4 \pm 15.9$ & $38.5 \pm 13.6$ \\
GK( $\left.{ }^{\circ}\right)$ & $70.2 \pm 20.1$ & $22.3 \pm 18.2$ & $24.1 \pm 17.6$ & $46.1 \pm 11.5$ \\
C7-SVA (cm) & $15.5 \pm 5.8$ & $5.1 \pm 7.5$ & $6.3 \pm 6.8$ & $10.6 \pm 5.6$ \\
PT $\left(^{\circ}\right)$ & $37.8 \pm 10.7$ & $22.5 \pm 7.5$ & $23.1 \pm 6.9$ & $14.7 \pm 7.8$ \\
PI $\left(^{\circ}\right)$ & $41.7 \pm 9.8$ & $42.9 \pm 9.9$ & $42.7 \pm 9.7$ & $1 \pm 5.8$ \\
SS $\left(^{\circ}\right)$ & $4.2 \pm 10.3$ & $20.4 \pm 9.8$ & $21.6 \pm 8.9$ & $17.4 \pm 8.9$ \\
\hline
\end{tabular}

TK Thoracic kyphosis, LL Lumbar lordosis, GK Global kyphosis, SVA Sagittal vertical axis, PT Pelvic tilt, PI Pelvic incidence, SS Sacral slope

technique for treating degenerative kyphoscoliosis using a mini-open PSO combined with percutaneous pedicle screws [15]. Chou reported 2 patients treated with the same technique [16]. The 2 patients, both with flat-back syndrome, underwent percutaneous fixation above and below the PSO, and the PSO was performed in a miniopen fashion. Charles [21] reported a 30-year-old female who had AS-related kyphosis who was treated with a combined open and percutaneous approach.

Prior to the development of the technique described herein, we used a technique similar to that described above for treating AS-related kyphosis. The combination of percutaneous screw placement and mini-open PSO significantly decreased the length of the incision (Fig. 5).

As we advanced our technique, we realized that it was possible to alleviate the use of percutaneous screws. By improving the operating procedure, both screw placement and PSO can be done through one incision; this is because some screws can be inserted after PSO, rather than before PSO as in a traditional PSO surgery. When the posterior part of spine is shortened as the osteotomy is closed, more facet joints can be reached through the already existing incision. For example, a mini-open PSO begins with screw placement at L1 and L3, followed by a PSO at L2, and concludes with screw placement at T12 and L4. All the manipulations can be done through the same incision. In addition, the use of a modified operating table makes closing the osteotomy more controllable and less difficult, and thus makes the whole procedure more feasible. The average length of the incision in the 25 patients was $10.2 \mathrm{~cm}$, which is significantly shorter

Table 2 Intraoperative and Postoperative Results

\begin{tabular}{ll}
\hline & One-level PSO $(\mathbf{n}=\mathbf{2 5})$ \\
\hline Length of incision(cm) & $10.2 \pm 1.2$ \\
Number of fusion levels & 4 \\
Estimated blood loss(ml) & $840.0 \pm 417.1$ \\
Operative time(min) & $263.0 \pm 50.4$ \\
Time to mobilization(days) & $4.1 \pm 1.3$ \\
\hline
\end{tabular}

PSO Pedicle subtraction osteotomy than that in traditional PSO surgery. As such, we believe that mini-open PSO surgery is superior to PSO surgery in terms of cosmetics.

\section{How effective is one-level mini-open PSO?}

The average final correction of the 25 patients was $46.1^{\circ}$, which is considered an excellent outcome as most studies report corrections of around $40^{\circ}$ (Table 3 ).

In recent years, more attention has been paid to sagittal spinal alignment during the correction of spinal deformities [22-24]. Schwab et al. proposed that SVA, PT, and PI-LL mismatch are the 3 most important spinopelvic parameters that should be carefully considered in the preoperative planning for treating adult spinal deformities. To achieve good clinical outcomes, the realignment objectives have been reported to be an SVA $<50 \mathrm{~mm}$, $\mathrm{PT}<25^{\circ}$, and PI-LL equal to $\pm 9^{\circ}$ [25]. More recently, Huang et al. reported that PT was the major radiographic contributor to ODI score at the last follow-up in patients with ankylosing spondylitis [26]. The optimal sagittal alignment parameters at the 2-year follow-up of adult spinal deformity patients who underwent one-level $\mathrm{PSO}$ were a $\mathrm{PT}<24^{\circ}$, spinosacral angle $(\mathrm{SSA})>108^{\circ}, \mathrm{T} 1$ pelvic angle (TPA) $<22^{\circ}$, and spinopelvic angle $(\mathrm{SPA})>$ $152^{\circ}$. The average PT of the 25 patients in this study was $23.1^{\circ}$, which can be considered a satisfactory outcome according to the aforementioned criteria.

\section{How many levels should be instrumented?}

Usually, 4-6 segments are instrumented in a PSO surgery $[27,28]$. In other words, pedicle screws are inserted into at least 2 segments above and below the osteotomy level. In the study by Zhu et al.[27], an average of 5.1 segments was instrumented. Huang et al. compared long and short instrumentation in patients with AS-related kyphosis [26]. Sixty-four patients who underwent onelevel PSO were divided into a short-segment group (17 patients, 4.5 segments instrumented) and a longsegment group (47 patients, 7.4 segments instrumented). The authors concluded that both long- and shortsegment instrumentations can ensure maintenance of 


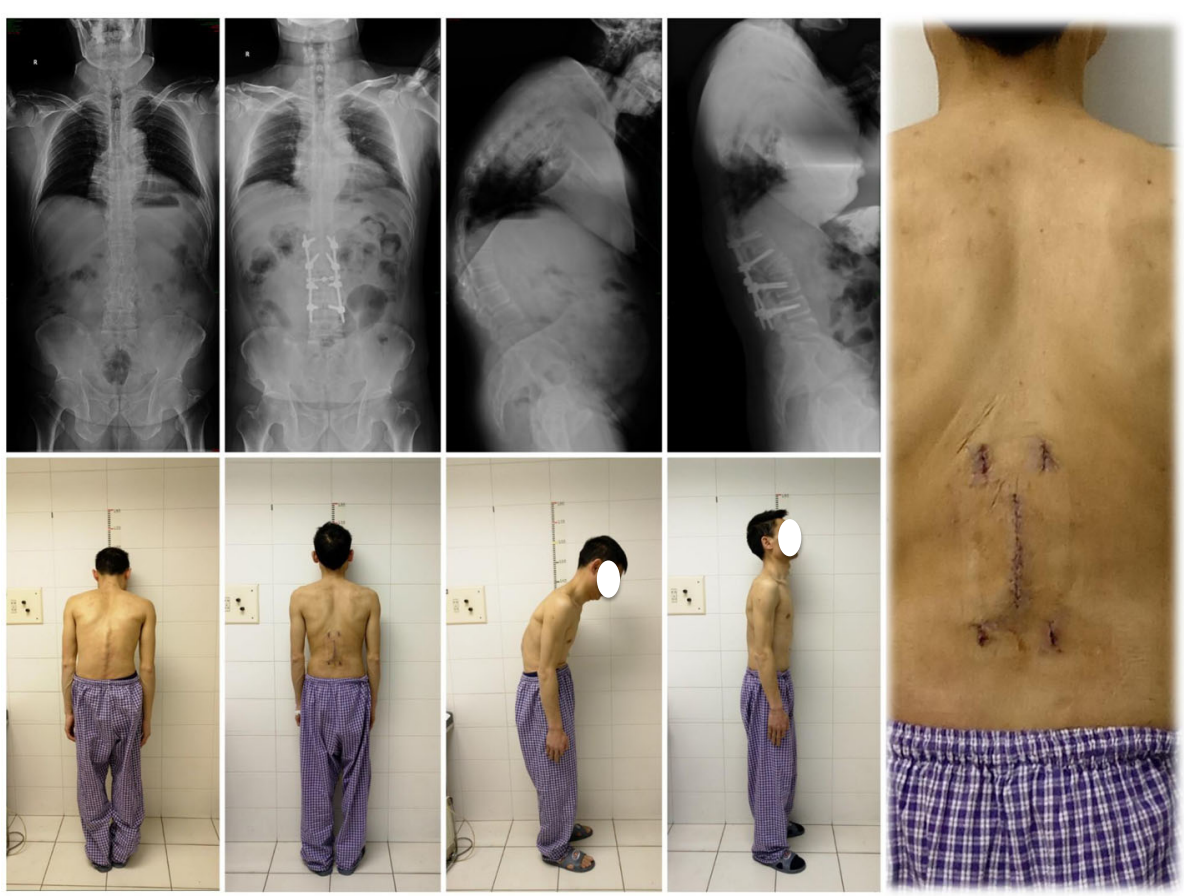

Fig. 5 Prior to development of the current technique, we used a technique combining percutaneous screw placement and mini-open PSO, which required multiple incisions

kyphosis correction, without obvious loss of correction. The extension of fused segments might not avoid instrumentation-related complications such as PJK or rod breakage in patients without fully ossified thoracolumbar structures. All 25 patients in this study received 4-segment instrumentation, and no implant-related complications occurred during the 2-year follow-up. We believe that instrumentation of 4 segments (2 segments above and below the osteotomy level) should be sufficient for a one-level PSO, because immediate 3-column stability of spine can be achieved when the osteotomy is completely closed, and hence there is no need for a longer instrumentation.

\section{The modified operating table}

In traditional PSO surgery, patients are placed prone on a regular operating table, which is flexed in a reverse $\mathrm{V}$ shape. Once the PSO is completed, the operating table is hyperextended to a V-shape, during which the osteotomy is gradually closed and the kyphotic spinal deformity is corrected. For our procedure, we use a modified operating table which consists of 6 independent

Table 3 Comparisons to the literature

\begin{tabular}{|c|c|c|c|c|c|c|c|}
\hline Author & No./age(yr) & Preop GK( $\left(^{\circ}\right)$ & Final correction $\left({ }^{\circ}\right)$ & Final SVA (cm) & Final $\mathrm{PT}\left({ }^{\circ}\right)$ & Operation time(min) & Blood loss (ml) \\
\hline Zhu(2012) [27] & $31 / 36$ & 73.7 & 39.9 & 7.7 & N/A & N/A & 1740 \\
\hline Xu(2015) [28] & $37 / 37$ & N/A & 38.4 & 5.8 & 29.2 & 232 & 1240 \\
\hline Liu(2015) [20] & $55 / 34$ & 75.3 & 43.6 & N/A & N/A & 381 & 2729 \\
\hline Hua(2017) [23] & $12 / 39.5$ & 75.2 & 38.7 & 10.8 & 44.5 & 327 & 1525 \\
\hline Qiao(2018) [24] & $17 / 35.3$ & 67.56 & 39.4 & 6.4 & N/A & N/A & N/A \\
\hline Qiao(2018) [24] & $47 / 34.2$ & 74.28 & 44.4 & 5.2 & N/A & N/A & N/A \\
\hline Xin(2019) [6] & $339 / 34.8$ & 55.8 & 44.6 & 5.2 & N/A & 253 & 537 \\
\hline Huang(2019) [26] & $100 / 34.7$ & 71.6 & 47.6 & 4.5 & 23.3 & 332 & 1821 \\
\hline Wang(2019) [5] & $27 / 40.3$ & 50.6 & 28.9 & 8.7 & N/A & 301 & 1452 \\
\hline Wang(2019) [5] & $30 / 37$ & 49.3 & 31.7 & 5.2 & N/A & 279 & 1150 \\
\hline Current study & $25 / 39.5$ & 70.2 & 46.1 & 4.9 & 23.1 & 263 & 840 \\
\hline
\end{tabular}


supports. The height of each support can be adjusted separately so that the shape of the operating table can be adjusted to fit that of the patient. Adjusting the supports allows the osteotomy to be closed in a more controllable manner so that vertebral subluxation can be prevented.

\section{Conclusions}

The current report shows that one-level PSO can be performed through an incision of about $10 \mathrm{~cm}$. The onelevel mini-open PSO could be superior to traditional PSO surgery with respect to cosmetic outcomes. Further comparative studies are necessary to evaluate the current and conventional techniques.

YW designed the concept of this study and drafted the manuscript. LL collected the clinical data. LTQ and $\mathrm{CDL}$ analyzed and interpreted the data. All authors have read and approved the final manuscript.

\author{
Abbreviations \\ AS: Ankylosing spondylitis; PSO: Pedicle subtraction osteotomy; SPO: Smith- \\ Petersen osteotomy; TK: Thoracic kyphosis; LL: Lumbar lordosis; GK: Global \\ kyphosis; SVA: Sagittal vertical axis; PT: Pelvic tilt; PI: Pelvic incidence; \\ SS: Sacral slope
}

\section{Acknowledgements}

None.

\section{Authors' contributions}

YW designed the concept of this study and drafted the manuscript. LL collected the clinical data. LTQ and CDL analyzed and interpreted the data. All authors have read and approved the final manuscript.

\section{Funding}

No funds were received in support of this work. No benefits in any forms have been or will be received form a commercial party related directly or indirectly to the subject of this manuscript

\section{Availability of data and materials}

All data generated or analysed during this study are included in this published article [and its supplementary information files].

\section{Ethics approval and consent to participate}

The study was approved by the Medical Ethics Committee of Peking University First Hospital (the ethics approval number provided by the board was 20190309052). All participants signed an informed consent for participation in this study.

\section{Consent for publication}

Written informed consents for publication of topless photographs and whole spine radiographs in the anatomic position were obtained from the patients.

\section{Competing interests}

All authors declare they have no conflict of interest.

Received: 6 April 2020 Accepted: 11 January 2021

Published online: 22 January 2021

\section{References}

1. Liu H, Yang C, Zheng Z, Ding W, Wang J, Wang H, Li S. Comparison of Smith-Petersen osteotomy and pedicle subtraction osteotomy for the correction of thoracolumbar kyphotic deformity in ankylosing spondylitis: a systematic review and meta-analysis. Spine. 2015;40(8):570-9.

2. Koller H, Koller J, Mayer M, Hempfing A, Hitzl W. Osteotomies in ankylosing spondylitis: where, how many, and how much? Eur Spine J. 2018;27(Suppl 1):70-100.
3. Zheng G, Song K, Yao Z, Zhang Y, Tang X, Wang Z, Zhang X, Mao K, Cui G, Wang $Y$. How to calculate the exact angle for two-level osteotomy in ankylosing spondylitis? Spine. 2016;41(17):E1046-52.

4. Buell TJ, Nguyen JH, Mazur MD, Mullin JP, Garces J, Taylor DG, Yen CP, Shaffrey ME, Shaffrey Cl, Smith JS. Radiographic outcome and complications after single-level lumbar extended pedicle subtraction osteotomy for fixed sagittal malalignment: a retrospective analysis of 55 adult spinal deformity patients with a minimum 2-year follow-up. J Neurosurg Spine. 2018;30(2): 242-52.

5. Wang $T$, Zheng $G$, Wang $Y$, Zhang $X$, Hu F, Wang Y. Comparison of 2 surgeries in correction of severe kyphotic deformity caused by ankylosing spondylitis: vertebral column decancellation and pedicle subtraction osteotomy. World Neurosur. 2019;127:e972-8.

6. Xin Z, Zheng $G$, Huang $P$, Zhang $X$, Wang $Y$. Clinical results and surgery tactics of spinal osteotomy for ankylosing spondylitis kyphosis: experience of 428 patients. J Orthop Surg Res. 2019;14(1):330.

7. Huang JC, Qian BP, Qiu Y, Wang B, Yu Y, Zhu ZZ, Hu J, Qu Z. Quality of life and correlation with clinical and radiographic variables in patients with ankylosing spondylitis: a retrospective case series study. BMC Musculoskelet Disord. 2017;18(1):352

8. Sugrue PA, O'Shaughnessy BA, Nasr F, Koski TR, Ondra SL. Abdominal complications following kyphosis correction in ankylosing spondylitis. J Neurosurg Spine. 2009;10(2):154-9.

9. Qian BP, Huang JC, Qiu Y, Wang B, Yu Y, Zhu ZZ, Mao SH, Jiang J. Complications of spinal osteotomy for thoracolumbar kyphosis secondary to ankylosing spondylitis in 342 patients: incidence and risk factors. J Neurosurg Spine. 2018;30(1):91-8.

10. Ravinsky RA, Ouellet JA, Brodt ED, Dettori JR. Vertebral Osteotomies in Ankylosing Spondylitis-Comparison of Outcomes Following Closing Wedge Osteotomy versus Opening Wedge Osteotomy: A Systematic Review. Evidence-based spine-care journal. 2013;4(1):18-29.

11. Song K, Zheng G, Zhang Y, Zhang X, Mao K, Wang Y. A new method for calculating the exact angle required for spinal osteotomy. Spine. 2013; 38(10):E616-20

12. Wang $T$, Zhao $Y$, Liang $Y$, Zhang $H$, Wang Z, Wang Y. Risk factor analysis of proximal junctional kyphosis after posterior osteotomy in patients with ankylosing spondylitis. J Neurosurg Spine. 2018;29(1):75-80.

13. Zhang $X$, Zhang Z, Wang J, Lu M, Hu W, Wang Y, Wang Y. Vertebral column decancellation: a new spinal osteotomy technique for correcting rigid thoracolumbar kyphosis in patients with ankylosing spondylitis. Bone Joint J. 2016;98-b(5):672-8.

14. Mao SH, Feng ZX, Qian BP, Qiu Y. The clinical relevance of the presence of bridging syndesmophytes on kyphosis correction and maintenance following pedicle subtraction osteotomy for thoracolumbar kyphotic deformity in ankylosing spondylitis: a comparative cohort study. BMC Musculoskelet Disord. 2018;19(1):97.

15. Wang MY, Madhavan K. Mini-open pedicle subtraction osteotomy: surgical technique. World Neurosurg. 2014;81(5-6):843.e811-844.

16. Chou D, Lau D. The mini-open pedicle subtraction osteotomy for flat-back syndrome and kyphosis correction: operative technique. Operative Neurosurg (Hagerstown Md). 2016;12(4):309-16.

17. Wang MY, Bordon G. Mini-open pedicle subtraction osteotomy as a treatment for severe adult spinal deformities: case series with initial clinical and radiographic outcomes. J Neurosurg Spine. 2016;24(5): 769-76.

18. Liu ZJ, Qian BP, Qiu Y, Mao SH, Jiang J, Wang B. Does relocation of the apex after osteotomy affect surgical and clinical outcomes in patients with ankylosing spondylitis and thoracolumbar kyphosis? J Neurosurgery Spine. 2019:31(1):27-34.

19. Hu X, Thapa AJ, Cai Z, Wang P, Huang L, Tang Y, Ye J, Cheng K, Shen H. Comparison of smith-petersen osteotomy, pedicular subtraction osteotomy, and poly-segmental wedge osteotomy in treating rigid thoracolumbar kyphotic deformity in ankylosing spondylitis a systematic review and metaanalysis. BMC Surg. 2016;16:4.

20. Liu Y, Ma Z, Gu X. Gender of patients and level of osteotomy are predictive factors for blood loss in ankylosing spondylitis patients undergoing pedicle subtraction osteotomy. Int J Clin Exp Med. 2015;8(6):9708-15.

21. Charles YP, Ntilikina Y, Collinet A, Steib JP. Combined percutaneous and open instrumentation for thoracolumbar kyphosis correction by two-level pedicle subtraction osteotomy in ankylosing spondylitis. Eur J Orthopaedic. Surg Traumatol. 2020;30(5):939-47. 
22. Ferrero E, Liabaud B, Henry JK, Ames CP, Kebaish K, Mundis GM, Hostin R, Gupta MC, Boachie-Adjei O, Smith JS, et al. Sagittal alignment and complications following lumbar 3-column osteotomy: does the level of resection matter? J Neurosurg Spine. 2017;27(5):560-9.

23. Hua WB, Zhang YK, Gao Y, Liu XZ, Yang SH, Wu XH, Wang J, Yang C. Analysis of sagittal parameters in patients undergoing one- or two-level closing wedge osteotomy for correcting thoracolumbar kyphosis secondary to ankylosing spondylitis. Spine. 2017:42(14):E848-54.

24. Qiao M, Qian BP, Zhao SZ, Qiu Y, Wang B, Jiang J. Clinical and radiographic results after posterior wedge osteotomy for thoracolumbar kyphosis secondary to ankylosing spondylitis: comparison of long and short segment. World neurosurgery. 2018;117:e475-82.

25. Schwab FJ, Patel A, Shaffrey Cl, Smith JS, Farcy JP, Boachie-Adjei O, Hostin RA, Hart RA, Akbarnia BA, Burton DC, et al. Sagittal realignment failures following pedicle subtraction osteotomy surgery: are we doing enough?: Clinical article. J Neurosurg Spine. 2012;16(6):539-46.

26. Huang JC, Qian BP, Qiu Y, Wang B, Yu Y, Qiao M. What is the optimal postoperative sagittal alignment in ankylosing spondylitis patients with thoracolumbar kyphosis following one-level pedicle subtraction osteotomy? Spine J. 2019;20(5):765-75.

27. Zhu Z, Wang X, Qian B, Wang B, Yu Y, Zhao Q, Qiu Y. Loss of correction in the treatment of thoracolumbar kyphosis secondary to ankylosing spondylitis: a comparison between Smith-Petersen osteotomies and pedicle subtraction osteotomy. J Spin Disord Tech. 2012;25(7):383-90.

28. Xu H, Zhang Y, Zhao Y, Zhang X, Xiao S, Wang Y. Radiologic and clinical outcomes comparison between single- and two-level pedicle subtraction osteotomies in correcting ankylosing spondylitis kyphosis. Spine J. 2015; 15(2):290-7.

\section{Publisher's Note}

Springer Nature remains neutral with regard to jurisdictional claims in published maps and institutional affiliations.

Ready to submit your research? Choose BMC and benefit from:

- fast, convenient online submission

- thorough peer review by experienced researchers in your field

- rapid publication on acceptance

- support for research data, including large and complex data types

- gold Open Access which fosters wider collaboration and increased citations

- maximum visibility for your research: over $100 \mathrm{M}$ website views per year

At $\mathrm{BMC}$, research is always in progress.

Learn more biomedcentral.com/submissions 